Note: This is a pre-copy-editing, author-produced PDF of an article accepted for publication in Substance

Use \& Misuse following peer review. The definitive publisher-authenticated version [McElrath K (2001) Risk behaviors among injecting drug users in Northern Ireland, Substance Use \& Misuse 36(14), 2137-57] is available online at $\mathrm{http}: / / \mathrm{www}$.informaworld. com/smpp/content $\sim \mathrm{db}=\mathrm{all} \sim$ content $=\mathrm{a} 713733499$

\title{
Risk Behaviors among Injecting Drug Users in Northern Ireland
}

\author{
Karen McElrath, Ph.D.* \\ Queen's University, Belfast, U.K. \\ Published in Substance Use \& Misuse (2001) 36(14), 2137-57
}

\begin{abstract}
Compared to elsewhere in the United Kingdom, drug policy in Northern Ireland has for the most part failed to incorporate harm reduction strategies. In light of the conservative drug policies, the purpose of this study was to investigate the nature and extent of risk behaviors among injecting drug users (IDUs) in Northern Ireland. Data for this study were drawn from in-depth interviews with 39 IDUs in Northern Ireland. The findings suggest that most IDUs engage in extensive risk behaviors that pose risk for HIV, Hepatitis B and C, and other infectious disease. Moreover, these risk behaviors are linked to the scarcity of new needles and a general lack of knowledge about injection practices that reduce risk for infectious disease. These findings are discussed in the context of conservative drug policies.
\end{abstract}

Key Words: Injection drug users; Risk behaviors; Drug policy; Needle sharing

\section{INTRODUCTION}

Most research in Northern Ireland has concentrated on issues relating to the Irish political conflict. For example, scholars have focused on the historical aspects of the conflict $(1,2)$, paramilitary groups $(3,4)$, the law and legal system (5), media portrayals of the conflict (6), victims of the conflict (7), state violence $(8,9)$, and the latest peace process (10). One disadvantage of this focus is that few studies have examined aspects of health and social behavior in the region. Research into drug misuse is by no means an exception; compared to other industrialized cultures, drug misuse studies in Northern Ireland emerged late - in the 1990s_and have concentrated largely on drug use prevalence among youth. In Northern Ireland, several health professionals as well as government officials have long maintained that heroin use has presented few problems in the region (11). These conclusions have been based on self-report studies and public health indicators of heroin use and injecting in the region. For instance, self-report studies of adults and youth in Northern Ireland have generally shown that the prevalence of heroin use is low, i.e., approximately $1 \%$ or less $(12,13)$. However, survey methods are likely to exclude or underrepresent heroin users; when heroin users are included in the sample, researchers have suggested that they are likely to display high rates of refusal or to underreport drug use $(14,15)$.

Public health indicators of heroin use and injection in Northern Ireland also have suggested low levels of use. For example, local physicians are required to notify the Chief Medical Officer in Northern Ireland if they attend a patient who is "addicted" to one or more specified drugs (i.e., several opiates, cocaine). Notification can be based on suspected addiction, if that diagnosis is based on "reasonable" grounds. Notification data from Northern Ireland showed slight increases through year-end 1996, however, in 1997, the number of notified "addicts" reached 162 (16), a substantially higher figure than in previous years. In 1998, the number of notified "addicts" increased to 229 , the highest number ever recorded from this data source. Further, $70 \%$ of the persons notified in 1998 were suspected or known to have "misused" heroin. These data are limited in that they depend greatly on physician subjectivity with regards to the concept of 
"addiction." Notification data can also be affected by the degree of compliance among physicians as well as an increase in the number of persons seeking treatment (17).

Reports of HIV infections with injecting drug use as the likely mode of transmission indicate very low numbers in Northern Ireland. Cumulative data through June 2000 reveal seven cases of HIV infection for this category (18), with the first case having been reported in 1987 (19) [the 1997 total population of Northern Ireland was estimated to be approximately 1,675,000 persons (20)]. Moreover, fewer than 20 new cases of Hepatitis $C$ infection with a reported risk factor of injecting drug use were reported in 1998 (21). These data suggest that infection rates are low, however, the data are based on voluntary testing and little is known about the extent of routine testing among injecting drug users (IDUs) in Northern Ireland. Further, studies that investigate the prevalence of HIV and Hepatitis C among injectors in Northern Ireland are lacking.

In some ways, the government perspective on heroin use coincides with the findings from much of the available data. However, if the notification data are in any way an accurate reflection of an increase in users, the official view has failed to consider this increase. Equally important, research that investigates heroin or injecting drug use in Northern Ireland is lacking, therefore data that might dispute these official claims have not been available. Some researchers have viewed the public health indicators of illicit drug use in Northern Ireland with skepticism, largely because data collection is hindered by extensive social stigma surrounding drug use, and, in particular, heroin and injection (22). Specifically, heroin users often are fearful that police, paramilitaries, and antidrug vigilantes ${ }^{1}$ will discover their drug use, and for some, these fears can affect their willingness to seek drug treatment, or be tested for HIV and other infectious diseases associated with drug injection (24).

One consequence of the official claims about low levels of heroin use is that drug policies in Northern Ireland relating to heroin and injection differ substantially from elsewhere in the United Kingdom, as well as in the Republic of Ireland. For example, needle exchange schemes were not implemented until 2001. Treatment services for heroin users are quite limited in Northern Ireland; methadone maintenance programs have not been implemented and methadone prescribing is strongly discouraged (at times the prescribing physician receives a written reprimand from the Chief Medical Officer). Therapeutic communities are not available and self-help groups, such as Narcotics Anonymous, for the most part are found in the Belfast area only. Additionally, organized street outreach services that assist drug users or injectors have yet to be implemented in Northern Ireland. The present study investigates risk behaviors, namely injection behaviors and practices, among heroin users in Northern Ireland. The methods by which IDUs manage drug lifestyles in the context of considerable social stigma and conservative drug policies are the primary focus of this paper. The study represents one of the first research investigations into heroin use and associated risk behaviors in the region.

\section{METHODS}

The overall study was based on in-depth interviews with 43 current or former users of heroin who had used heroin (injected or "chased the dragon"2) in Northern Ireland. Given the exploratory nature of the study and the limited research into heroin use in the region, "any use of heroin in Northern Ireland" was the only criterion for study participation. The study commenced in September 1997, although the majority of interviews were conducted in 1998 and 1999. Respondents were recruited largely through "gatekeepers" and "snowball sampling" (27) whereby persons who completed an interview were asked to refer other persons (e.g., friends, acquaintances, partners) who had used heroin. These sampling strategies are instrumental for

\footnotetext{
${ }^{1}$ Anti-drug vigilantes in Northern Ireland are individuals who are vehemently opposed to illicit drug use. Their actions have included violent assaults directed largely against alleged drug dealers. One group, calling itself, Direct Action Against Drugs (DAAD), has claimed responsibility for the deaths of several suspected drug dealers in Northern Ireland

${ }_{2}^{2} 2$ "Chasing the dragon" represents one route of administering heroin. Although techniques can vary, generally the drug is placed on tin foil and heated from beneath the foil. The vapors are then inhaled by the user $(25,26)$.
} 
reaching hidden populations such as illicit drug users (28). Once a potential respondent made contact with the interviewer, the interviewer then described the purposes of the study (e.g., that the research focused on health and various lifestyle issues pertaining to heroin use). The interviewer also stated that she had been involved in studies of heroin use in the United States, and that research into heroin use in Northern Ireland was quite limited; the study hoped to fill that gap. The interviewer was employed as a university teacher and researcher in the Department of Sociology, Queen's University, Belfast. She was 38 years old when the study commenced, and her accent immediately identified her as a foreigner, an "outsider" with regards to the wider Irish political conflict. ${ }^{3}$ All individuals who made contact with the researcher and requested an interview subsequently completed an interview. However, a few respondents appeared for an interview weeks after the initial contact had been made. The number of heroin users who became aware of the study, but who never requested an interview is not known.

The interview guide consisted of a number of items relating to patterns of heroin use (e.g., frequency, dosage, age at onset, method of administration, patterns of use), risk behaviors associated with injection practices, descriptions of first, last and heaviest use of heroin, treatment experiences (including "self-help" strategies), interactions with medical staff regarding heroin use, and related lifestyle and attitudinal issues. Historical information on other drug use as well as demographic data were collected at the conclusion of the interview. Interviews were conducted within a one- to two-hour time frame and in various settings (e.g., university offices, respondents' homes). The interview required very basic communication skills of respondents who participated in the study. Although the interview guide was not formally pre-tested with a sample of heroin users, various questions were phrased differently in subsequent interviews based on responses from previous interviews. ${ }^{4}$ Given the reflexive nature of qualitative interviews, questions were added to subsequent interviews when important issues emerged in previous interviews.

Respondents were assured of anonymity and confidentiality, and paid P15-20 (US\$ 21.60-28.80) for their participation in the study. Several ethical protocols were followed in the study, in addition to the assurances of anonymity and confidentiality. First, the interview setting was determined by respondents' preferences, which provided some shift of the power relationship between interviewer and respondent. Second, respondents were reminded at various points during the interview, that they could end the interview at any time without consequence, and still be paid for limited participation (one respondent terminated the interview early, because of sickness associated with withdrawal). Third, although the study was anonymous and therefore final interview transcriptions could not be sent to study participants for comment, a draft final report was prepared (complete with quotations from anonymous respondents) and distributed to one gatekeeper for review. This gatekeeper, who maintained several informal contacts with current and former users, was asked specifically to identify any comments or text that might harm or identify a particular respondent, or that might harm heroin users generally.

The primary researcher conducted and transcribed all of the interviews. Clearly, studies which use interviewers from academia promote a differential balance of power between respondent and interviewer. The researcher utilized a number of strategies to reduce this power imbalance, such as introducing herself and asking respondents to refer to her by her first name, facing respondents directly without physical barriers such as desks, and offering to interview respondents in their homes. Additionally, for some respondents, the university affiliation provided credibility to the study and suggested that respondents' experiences were important.

\footnotetext{
${ }^{3} 3$ The extent to which the interviewer's outsider status affected study participation is not known. However, some users appeared to be pleasantly surprised that an outsider showed interest in their lifestyles.

${ }^{4}$ For example, the preliminary interviews included several terms (e.g., "booting") based on nomenclature associated with certain heroin user subcultures in the United States. Some of this nomenclature was unrecognizable among participants in the Northern Ireland study. The researcher learned the culturallyspecific nomenclature as the study continued.
} 


\section{Characteristics of the Sample}

Most study participants were male (N1/436) and respondents' ages ranged from 18 to 48

(mean $1 / 430$ years; median $1 / 429$ ). A number of respondents were uncomfortable with the question of religious background (i.e., Catholic or Protestant) or, equally important, ethnic identity (i.e., Irish or British). Therefore, these items were excluded from the demographic history component. The omission of these data precluded any external interest (e.g., from media) in determining whether heroin use was disproportionately associated with a particular religious or ethnic group, a finding that might have contributed to stereotypical assumptions about that group. The researcher did observe, however, that the majority of respondents in the study had used heroin in the company of injectors whose religious background differed from their own. Indeed, one Irish injector noted that he would have injected with a member of the British monarchy (023).

Approximately $50 \%$ of the sample (N1/422) had children, however, only nine respondents reported that their children lived with them at the time of the interview. Twenty-six percent $(\mathrm{N} 1 / 411)$ of the respondents were employed in part- or full-time work at the time of the interview, $7 \%$ were students, and $61 \%$ of the sample were unemployed (information was missing for three respondents). The preliminary interviews included a question about sources of income, however, several respondents were uncomfortable with this question, thus, the item was omitted in subsequent interviews. Although some of the respondents were born and raised in areas outside Belfast, most resided in Belfast at the time of the interview, thus, the sample is based largely on persons who resided in an urban setting during some or most of the heroin career. Their experiences may differ substantially from heroin users who live elsewhere in Northern Ireland. For example, a study conducted in Australia found that rural and urban injecting drug users differed in terms of their injecting practices, needle sharing, and prevalence and incidence of Hepatitis $C$ (29). A second study found fewer differences between rural and urban injectors in Scotland (U.K.), although urban IDUs had higher rates of HIV and were more likely to share injection equipment with persons outside their immediate social network (30).

The average age at which respondents initiated heroin use was 20 years and the majority (N1/426) had initiated heroin use in other countries. Thirty per cent of respondents (N1/413) had initiated heroin use through injection. About one-half (N1/421) initiated through chasing; 12\% (N1/45) initiated through snorting/sniffing, and 7\% through smoking (non-chasing). Data on route of administration at initiation was missing for one respondent. Of the 29 respondents who had initiated heroin use through non-injection, 25 had progressed to injection. The other four participants had chased but had never injected heroin, and thus are omitted from the present analysis (final $\mathrm{N}^{1} / 439$ ).

Heroin was the preferred drug of choice for most respondents, however, the vast majority of study participants had either never been exposed to or had never completed treatment for heroin use. The average length of time between the year of initiation into heroin use and the year of interview was 10.7 years (range 1 to29 years). Of the 39 injectors, 24 had been using heroin for ten or more years. However, usage since initiation varied considerably. For example, one respondent had used heroin and crack cocaine for five years, followed by a five-year period of abstinence. He reported "dabbling" (i.e., using infrequently and/or small amounts) with heroin in the year prior to the interview (011). Another reported that ten years prior to the interview he had been using 3.5 grams of heroin per day over a period of several months ("No one believed [that] I was using that much but I was"- 041). That pattern of usage was followed by a 16-month period during which he used small amounts, and on a few occasions only. Another reported using 0.5 to 1 gram of heroin per day for 14 to 15 years. His last injection occurred three months prior to the interview, and he purposely abstained from injection since that time. However, he had chased the drug on several occasions during that time, preferring that method of ingestion because, "I'm trying to get off it" (014). 
Only four persons reported current use of alcohol; one respondent indicated that alcohol was his drug of choice. Eighty-three percent of the sample smoked approximately 20 cigarettes daily. Ninety-eight percent of the respondents had consumed cannabis at some stage, and $35 \%$ of the sample (N1/415) had used cannabis daily during the six-month period prior to the interview. Ninetythree percent of the respondents had used hallucinogens (LSD or magic mushrooms), and 95\% had consumed Ecstasy (MDMA). Approximately half the sample ( $\left.\mathrm{N}^{1} / 421\right)$ had initiated Ecstasy use after heroin initiation, a finding that might reflect drug preferences, differences in drug markets, or the historical availability of Ecstasy in Northern Ireland (anecdotal evidence suggests that MDMA markets emerged largely in the 1990s).

Nearly all of the respondents (98\%) had used amphetamine, and approximately one-third had injected the drug. Ninety percent of the sample had snorted powder cocaine, with $63 \%$ reporting having had injected the substance. The majority of respondents $(80 \%)$ had used crack cocaine and several persons had injected crack cocaine, a behaviour that reportedly has been increasing in London (31). With the exception of heroin, other opiates, and cannabis, however, most respondents had not used these other drugs "regularly." For example, 12 persons had used cocaine (through snorting or injecting) during the six-month period prior to the interview, however, only three persons had used cocaine once a month or more during that time period. Similarly, only $5 \%$ had used amphetamine once a week or more in the six months prior to the interview.

Several respondents reported using other opiates, particularly when heroin was not available. Following heroin, Dihydrocodeine and Morphine Sulfate Tablets (MSTs) were the most common opiates used among respondents. Additionally, the majority of respondents had used Temazepam, largely to ease withdrawal symptoms associated with heroin use. Seventy-seven percent of respondents had injected Temazepam, however, manufacturers have now changed the drug's form, making it more difficult to inject.

\section{Trust and Validation}

Qualitative and ethnographic studies into illicit drug use in Northern Ireland were, for the most part, non-existent when the present study commenced. As a consequence, trusting relationships between drug researchers and drug users had never been developed. Obtaining access to the study population clearly presented difficulties. Additionally, the long history of political conflict has created a level of suspicion about researchers who seek information. In some Irish nationalist neighborhoods, for example, residents maintain the perception that several years ago, members of the British Army posed as survey researchers in order to gather intelligence about people's lifestyles, and their houses. More recently, an Irish nationalist political party advised people that they should not participate in a particular survey for fear that the information might be used against them. Further, the largest republican paramilitary group, the Irish Republican Army (IRA), has maintained an anti-drug ideology for several years and members of that group have been involved in informal "policing" within various neighborhoods.

The nature of the political conflict also affects Protestant drug users, particularly when they reside in neighborhoods characterized by a heavy loyalist paramilitary ${ }^{5}$ presence. For example, one Protestant respondent had been prescribed dihydrocodeine by his physician but purposely avoided his local pharmacy for fear that his identity as a "drug user" would be disclosed to local paramilitaries. Another Protestant male voiced considerable fears about loyalist paramilitaries, and only came forth for an interview after repeated telephone conversations with and reassurances by the researcher. These concerns are firmly embedded in local folklore within several heroin user sub-cultures.

\footnotetext{
5 Loyalists are persons-largely Protestant-who believe that Northern Ireland should remain within the United Kingdom, hence they are "loyal" to the British Crown. Further, loyalists tend to believe that violence is justified in the pursuit of maintaining the tie with Britain
} 
To begin the process of establishing trust, the researcher first made contact with a former heroin user who had been "clean" for four years. He had disclosed his past drug use to several people (i.e., non-users) in the community and was quite willing to meet with the researcher. He provided several suggestions for recruitment and later served as an important gatekeeper. To facilitate trust with respondents, the researcher often showed them articles on drug use that she had authored. At other times, the researcher provided her home telephone number as a point of contact.

This decision was a conscious one, the assumption being that potential respondents might be more willing to trust the research if the researcher could demonstrate that she trusted potential respondents. To illustrate further, the researcher was on an 18-week maternity leave midway through the study. Fieldwork with hidden populations, however, cannot realistically cease for 18 weeks and then recommence. The decision was made to continue with interviewing during the period of maternity leave, and with study participants' approval, the researcher's young infant accompanied her to the interview site (including participants' homes). The initial intent was for practical reasons only, however, in time the researcher observed that interviews which occurred in these settings yielded extremely productive data and discussion. Most of the other strategies were used in order to promote trust and to generate comfortable interview settings for the respondents. Despite these attempts, however, ". . . we can never be certain of how members of such communities perceive us" (32).

\section{RESULTS}

The majority of study participants reported great difficulties in obtaining new needles/syringes to be used for injecting heroin and other drugs. Needles/syringes are most often sold from pharmacies in packages of 10 at a cost of two pounds sterling (US\$2.88). Pharmacists, however, use their discretion in the decision to sell. Nearly all of the respondents reported at least one instance whereby a pharmacist refused to sell them needles/syringes. Several respondents reported that these refusals occurred on a regular basis (discussed below). The limited supply of needles as well as the cost of purchasing needles, contributed to a number of behaviors that pose risk for HIV, Hepatitis C and other infectious diseases, and contribute to ill-health in general.

\section{Obtaining Needles/Syringes}

A number of difficulties were reported by respondents who tried to purchase needles from chemists, particularly in areas outside Belfast (e.g., 029, 030).

"One chemist sold out of decency. Another chemist stopped selling when the deaths occurred ... [A third chemist required you] to sign your name" [for needles but not for prescription or over-the counter drugs] (004, male).

This participant reported that IDUs within his injecting group did not often buy needles from chemists because "too many people, going back too often would spoil it for us." (004). A participant who lived in a small town reported that he never purchased needles from a chemist there because, "They all know my family" (034).

One study participant reported that he purchased needles from dealers in the town of Ballymena because chemists in the area will not sell them to him (030). A few Belfast respondents reported that Belfast users have "swapped needles for gear [heroin] in Ballymena"6 (001). Indeed, when this researcher asked a few users how she could recruit other respondents from Ballymena, one

\footnotetext{
${ }^{6}$ Ballymena is located approximately 30 miles north of Belfast. Compared to IDUs in cities located outside Northern Ireland, these transactions are unusual in that urban users often travel to a smaller town in order to buy heroin.
} 
suggested that she offer new needles/syringes as opposed to money as an incentive for study participation.

Most of the Belfast users reported that chemists refused to sell needles/syringes to them at various times. For some persons, refusals occurred frequently. Some perceived that a successful purchase depended on the "way you looked " (006), or never visiting the same chemist twice (048). The interview data clearly suggested that most respondents had made several attempts to purchase new needles but faced with structural barriers, were forced to use various negotiation skills in order to obtain the injecting equipment. For example, several respondents attempted to "disguise" their drug injector identity by portraying themselves as diabetics. Others recalled that they had informed a chemist that a diabetic relative needed to inject insulin but that the relative needed a new supply of needles. In these situations, many respondents requested a particular size (e.g., $1 \mathrm{ml}$ ) and dimension (e.g., micro fine) of needle: "You have to know what you're asking for" (027). Some reported that a few chemists were willing to sell them $2 \mathrm{ml}$ needles but that this size of needle was unacceptable for injecting, in part because of the problems that it posed for veins (051). A few respondents eventually avoided pharmacists altogether:

"I've got no money for works. [l've] tried to buy here but most chemists wouldn't sell them and I didn't know the diabetic lingo" (053).

Others collected needles/syringes from exchange schemes that operate in other countries during visits to these other areas.

\section{Multiple Injections}

Needles are intended to be used one time only. However, the lack of available needles contributed greatly to multiple injections with the same needle. One respondent noted that he often used the same needle several times per day over a period of a few weeks (041). Another reported: "I've used one needle 14 times over a few days" (053, male, age 29).

Some estimated that they used one needle to inject as many as 30 times $(045,080)$ and one reported that his "jugular's messed as well" (045). Others were less precise, noting that "we'd use 'til they got blunt" (004) and using blunt works was described as "reversing a double decker into your arm" (071).

\section{Cleaning Injection Equipment}

Bleach is an extremely effective way to clean drug injection equipment and when used properly can inactivate the HIV found on such equipment (33). To their credit, some study participants reported that they used bleach to disinfect needles (008) and other injection equipment. One respondent made specific reference to bleach, and the sterilizing of spoons and other injection equipment (009). He also reported that when injecting within a group of IDUs he "would make sure it [the needle and syringe] would be clean for everyone."

A few study participants had never heard that bleach should be used to clean equipment (e.g., 003). Some used other, less effective means to clean needles, e.g., cold water (027), vodka (003). Younger IDUs with shorter injection careers have been found to engage in more risk behaviors than older IDUs (35). A male respondent in the present study noted that "long term users would use bleach" but as for less experienced injectors, he recalled that:

"Nobody had a clue. We got no information-only from other junkies. We just mimicked what we saw [other users do]" (004, initiated heroin use at age 25).

Data collected from study participants, however, indicated that experienced injectors also engaged in considerable risk behaviors for infectious disease. For example, a respondent who initiated heroin use in 1981 reported that he used a sterilizer todisi nfect needles, but only when 
he prepared toinjec $t$ at home (041). Another admitted that it was "difficult" to use bleach when he injected in the middle of the night (043, initiated heroin use nine years before the interview).

\section{“Sharing" Needles and Other Injection Equipment}

The term "needle sharing" has been described as a misnomer in that it suggests that the behavior represents "an act of reciprocity" based on the altruistic beliefs of the loaner (35). In fact, the lending and borrowing of needles is influenced greatly by their lack of availability (36). Nearly all of the injectors in the present study had at some point used another injector's needle/syringe. Some noted that they were less likely to borrow injection equipment in places where new needles/syringes were available, e.g., Dublin (Republic of Ireland), Glasgow (U.K.), and London (U.K.). The scarcity of new needles/syringes in Northern Ireland contributed greatly to the loaning and borrowing of this equipment:

“People use another's syringe if there's no option. I don't think they [health officials, government] understand that. It's the height of stupidity, to make it difficult to get syringes. . .We've no choice. . . people are driven by their desire to obtain" (051, has tested positive for Hepatitis C)

"l'd share [needles] with Hep C people" (045, age 32).

For some, the urgency to use heroin took precedence over a search for a new needle: "When you're sick enough, you'd use somebody else's"' (041, male, age 32).

Consistent with research findings reported elsewhere (36), the data drawn from the present study indicate that some study participants defined "sharing" in terms of their relationship with the loaner/borrower. That is, sex partners did not necessarily view the use of the partner's needle as a behavior that constitutes "sharing" $(001,002,003)$. A female respondent reported that she never "shared" needles, but later in the interview she noted that she and her boyfriend used the same needle/syringe on every occasion that they injected together (021). Another female reported that she and her boyfriend always shared needles and for the most part she appeared to be unconcerned about loaning their equipment: "It's up to anyone else if they wanted to use our needle" (035). A male respondent reported that he and his girlfriend always "shared" needles: "[We were having] unprotected sex, so why not?" (071, age 26).

Others noted the distinct possibility of "accidental" use of another's needle/syringe, despite attempts not to do so:

"I may have accidentally shared. l'd wake up-we'd both wake up and there'd be two [sets of works] on the table. [We couldn't recall] which one was whose." (074, male, age 43).

"At first, there 's no way that we'd share [with one another]. He set his here . . . and then after a while we wouldn't know whose needle was whose." (005, female)

"[At times] I can't remember which is my own" (073, female).

A few study participants acknowledged the importance of sterile needles but appeared lackadaisical about "borrowing" from others, even when they believed that the loaner was positive for HIV-antibodies. A female respondent reported that she did not often use bleach but did so during the last injection episode while in the company of two other IDUs. Prior to that event she had heard that one of the IDUs was HIV antibody positive. She made no attempt to clean the needle during the injection episode, although one of the IDUs who was present did so for her (073). 
Another respondent described a situation in which he was in the company of two other injectors, both of whom were HIV-antibody positive. The two IDUs injected first and the respondent recalled that he was hesitant to use the needle. One of the other IDUs showed him that they had placed plastic lining (from a carry/grocer bag) within the syringe and that this technique would protect the respondent from infectious disease, despite his use of the same needle. The respondent injected at that time and recalled that the other IDU had learned the "lining" technique while incarcerated in prison in the south of Ireland (080).

The data suggest that some study participants were unaware that other injection equipment (e.g., spoons, containers, water, cotton) and practices (separating drugs for use by two or more people) can serve as conduits for the spread of infectious diseases. In fact, some researchers have suggested that these methods might be responsible for the high incidence of Hepatitis $\mathrm{C}$ among injecting drug users (37). A male respondent described his most recent injection experience. Heroin or other drugs were not available so he injected the MST residue from another injector's filter:

"I know that person didn't have AIDS" (053, age 29).

Similarly, study participants noted the apparent lack of knowledge among other injectors:

"People [in NI] share spoons, etc. Hep C can live for some time on a spoon" (051, age 48).

"They thought they'd use my water . . they're careless" (009, age 25).

\section{DISCUSSION}

The results from the present study show that several IDUs in Northern Ireland engage in various behaviors that pose risk for infectious diseases. In particular, "sharing" (i.e., loaning or borrowing) of needles and other injection equipment can involve blood-borne contact which places injection drug users at risk for exposure to HIV, and Hepatitis B and C (38). In the present study, many of these risk behaviors appear to be related to the limited supply and availability of needles/syringes.

Drug policies can affect risk behaviors that contribute to the spread of infectious diseases such as HIV (39). HIV among IDUs in New York spread very quickly, and during that time sterile needles for use by IDUs were not widely available (40). The rapid spread of HIV in New York occurred also because IDUs were sharing with several other IDUs in friendship networks and within brief spans of time (38). In the late 1980s, laws that prohibited the possession of needles/syringes without prescription were not enforced in Glasgow, wherein the rate of HIV infection among injectors was $5 \%$. Alternatively, the rate of HIV was 50 percent among injectors in Edinburgh (U.K.), where needle possession laws were rigorously enforced (41). In fact, HIV among injectors spread very quickly, i.e., within twoyea rs, in Edinburgh (42) largely because of the restricted availability of injecting equipment" (43). Escalating HIV incidence rates within brief time periods also have been reported in other countries (40). For example, HIV among IDUs in Manipur, North India was virtually non-existent in 1989 but within one year the rate among IDUs had escalated to $54 \%(44)$.

In comparison to other European regions, available data regarding the prevalence and incidence of HIV among IDUs in Northern Ireland suggest that these rates are low. However, studies that examine the rate of voluntary testing among IDUs in Northern Ireland are lacking. Although treatment and medical professionals can encourage IDUs to seek testing for HIV antibodies, the majority of participants in the present study had never been exposed to formal treatment for heroin use and several had never disclosed their drug histories to medical or health professionals. These findings suggest the possibility that several IDUs in Northern Ireland have not undergone testing for HIV, in which case the official data are likely to be underestimated. 
Harm reduction policies have been shown to reduce the spread of HIV. Evidence suggests, for example, that in comparison to the United States, HIV failed to reach epidemic proportions in Australia largely because of the early implementation of several harm reduction policies, e.g., methadone, needle exchange, education for injectors (45). In particular, needle exchange programs have been found to affect the HIV seroprevalence rate. An international survey that included several cities (most located within the United States) found that seroprevalence declined by $5.8 \%$ per year in those cities that had offered needle exchange but had increased in those cities that did not offer needle exchange (46).

To date Northern Ireland for the most part, has failed to implement basic harm reduction strategies. In fact, drug policy in the region differs substantially from elsewhere in the United Kingdom. The degree to which current drug policy in Northern Ireland will contribute to the spread of HIV and other infectious diseases is not known. Data from this study, however, suggest that risk behaviors among IDUs in Northern Ireland are commonplace. Additionally, a number of IDUs in the present study initiated use in other countries, and in places that have (reportedly) higher rates of HIV infection among injectors than in Northern Ireland. Several other respondents had injected in other countries, and at various points in the heroin career. Travel between countries among the IDU population and during the injection career, has been identified as a major factor in introducing the virus to the home country (40). The geographic proximity of Northern Ireland to other high injecting areas should not be ignored. For example, the United Nations International Drug Control Programme (47) has identified six "factors" that "appear to facilitate the emergence of injection as a pattern of drug abuse," of which "geographical proximity to a country or region where injecting is commonplace" is included. The geographic proximity of Northern Ireland to regions characterized by large numbers of injectors (e.g., Dublin, Glasgow) when combined with extensive risk behaviors among IDUs should be of great concern to health and other government policymakers.

\section{STUDY LIMITATIONS}

Heroin users in Northern Ireland represent a marginalized and hidden population. The sampling strategy (largely snowball) and data collection procedure (in-depth interviews) were the most appropriate methods for studying members of this subculture. However, by relying on a nonrandom sample of heroin users, the extent to which the views expressed by respondents reflect the experiences of the population of heroin users in Northern Ireland is unknown. Therefore, drawing inferences to the general population of heroin users in Northern Ireland is inappropriate.

A second potential limitation focuses on one characteristic of the sample. Most studies of heroin users have relied on treatment sites and related agencies for recruitment of respondents. As a consequence, we have little information about heroin users who are not in contact with support services (48). In a sense, the present study filled this void to some extent in that the majority of respondents had never completed a treatment program and others had no exposure to treatment at all. Alternatively, the present study provides little information about persons who have completed drug user treatment in Northern Ireland and who have abstained from heroin for long periods of time. On several occasions the researcher sought to recruit heroin users from treatment sites but was not successful in this regard. 


\section{ACKNOWLEDGMENTS}

This study was funded in part by the Northern Ireland Drugs' Campaign in association with the Northern Ireland Statistics and Research Agency. Points of view are those of the author.

\section{REFERENCES}

1. Hachey, T.E. Britain and Irish Separatism: From the Fenians to the Free State,1867-192 2; Catholic University of America Press: Washington, D.C., 1984.

2. Kennedy-Pipe, C. The Origins of the Present Troubles in Northern Ireland; Longman: New York, 1997.

3. Bruce, S. The Red Hand: Protestant Paramilitaries in Northern Ireland; Oxford University Press: Oxford, 1992.

4. Coogan, T.P. The I.R.A.; HarperCollins: London, 1995.

5. Jennings, A., Editor. Justice Under Fire: The Abuse of Civil Liberties in Northern Ireland; Pluto: London, 1990.

6. Curtis, L. Ireland, The Propaganda War: The Media and the "Battle for Hearts and Minds"; Pluto: London, 1984.

7. Smyth, M.; Fay, M-T. Personal Accounts from Northern Ireland's Troubles: Public Conflict,Private Loss; Pluto: London, 2000.

8. Mullan, D. (Ed.); Scally, J. (Comp.). Bloody Sunday: Massacre in Northern Ireland: The Eyewitness Accounts; Roberts Rinehart: Niwot, Colorado, 1997.

9. Rolston, B. Unfinished Business: State Killings and the Quest for Truth; Beyond the Pale: Belfast, 2000.

10. O'Clery, C. The Greening of the White House; Gill and Macmillan: Dublin, Ireland, 1996. 11. Northern Ireland Affairs Committee. Illicit Drug Use in Northern Ireland. House of Commons, Session 1996-97. HMSO: London, 1996.

12. Miller, P.; Plant, M. Drinking, Smoking, and Illicit Drug Use among 15 and 16 Year Olds in the United Kingdom. Br. Med. J. 1996, 313, 394-397.

13. Northern Ireland Office. Patterns of Drug Use in Northern Ireland-Some Recent Survey Findings, 1996 -1997; Northern Ireland Statistics and Research Branch: Belfast, Northern Ireland, 1998.

14. Korf, D.J. Comparison of Different Estimation Methods in the Netherlands. In Estimating the Prevalence of Problem Drug Use in Europe; European Monitoring Centre for Drugs and Drug Addiction, Ed.; Office for Official Publications of the European Communities: Luxembourg, 1997; 199-214.

15. Ramsay, M.; Percy, A. A National Household Survey of Drug Misuse in Britain: A Decade of Development. Addiction 1997, 92, 931-937.

16. Department of Health and Social Services. Northern Ireland Drug Addicts' Statistical Information Bulletin,31 December 1998; Department of Health and Social Services Dundonald, Northern Ireland, 1998.

17. Mott, J. Notification and the Home Office. In Heroin Addiction and Drug Policy: The British System; Strang, J., Gossop, M., Eds.; Oxford University Press: Oxford, 1984; 270-291.

18. Public Health Laboratory Service. AIDS and HIV Infection in the United Kingdom: Monthly Report. Commun. Disease Rep. 2000, 10 (34), 309-310.

19. Public Health Laboratory Service. Personal Communication with Author. 2000, 21 February. 20. Northern Ireland Statistics and Research Agency. Mid-year Population Estimates in Northern Ireland-Validation and Extension to Local Government Districts; Northern Ireland Statistics and Research Agency: Belfast, Northern Ireland, 1998.

21. Public Health Laboratory Service. Personal Communication with Author. 2000, 21 February. 22. Higgins, K.; McElrath, K. The Trouble with Peace: The Cease-fires and their Impact on Drug Use among Youth in Northern Ireland. Youth Society, 2000, 32 (1), 29-59. 
23. McEvoy, K.; McElrath, K.; Higgins, K. Does Ulster Still Say No? Drugs, Politics, and Propaganda in Northern Ireland. J. Drug Issues 1998, 28, 127-154.

24. McElrath, K. Heroin Use in Northern Ireland,Final Report. Belfast: Northern Ireland Statistics and Research Agency: Belfast, Northern Ireland, 2000.

25. Griffiths, P.; Gossop, M.; Strang, J. Chasing the Dragon: The Development of Heroin Smoking in the United Kingdom. In Heroin Addiction and Drug Policy: The British System. Strang, J., Gossop, M., Eds.; Oxford University Press: Oxford, 1984; 121-133.

26. Strang, J.; Griffiths, P.; Gossop, M. Heroin Smoking by 'Chasing the Dragon': Origins and History. Addiction 1997, 92 (6), 673-683.

27. Biernacki, P.; Waldorf, D. Snowball Sampling: Problems and Techniques of Chain Referral Sampling. Sociol. Methods Res. 1981, 10, 141-163.

28. Fountain, J.; Griffiths, P. Synthesis of Qualitative Research on Drug Use in the European Union: Report on an EMCDDA Project. Eur. Addict. Res. 1999, 5, 4-20.

29. Aitken, C.; Brough, R.; Crofts, N. Injecting Drug Use and Blood-borne Viruses: A Comparison of Rural and Urban Victoria, 1990-95. Drug Alcohol Rev. 1999, 18, 47-52.

30. Haw, S.; Higgins, K. A Comparison of the Prevalence of HIV Infection and Injecting Risk Behaviour in Urban and Rural Samples in Scotland. Addiction 1998, 93, 855-863.

31. Hunter, G.M.; Donoghoe, M.C.; Stimson, G.V. Crack Use and Injection on the Increase among Injecting Drug Users in London. Addiction 1995, 90, 1397-1400.

32. Tewksbury, R.; Gagne' , P. Assumed and Presumed Identities: Problems of Self-presentation in Field Research. In Extreme Methods: Innovative Approaches to Social Science Research; Miller, J.M., Tewksbury, R., Eds.; Allyn and Bacon: Needham Heights, Massachusetts, 2001; 7293.

33. Shapshak, P.; McCoy, C.B.; Rivers, J.E.; Chitwood, D.D.;Mash, D.C.; Weatherby, N.L.; Inciardi, J.A.; Shah, S.M.; Brown, B.S. Inactivation of Human Immunodeficiency Virus-1 at Short Time Intervals using Undiluted Bleach. J. Acquir. Immune Defic. Syndr. 1993, 6, 218-219.

34. Friedman, S.R.; Des Jarlais, D.C.; Neaigus, A.; Abdul-Quader, A.; Sotheran, J.L.; Sufian, M.; Tross, S.; Goldsmith, D. AIDS and the New Drug Injector. Nature 1989, 339, 333-334.

35. Koester, S.K. Copping, Running, and Paraphernalia Laws: Contextual Variables and Needle Risk Behavior among Injection Drug Users in Denver. Hum. Organ 1994,53 , 287-295.

36. McKeganey, N.; Barnard, M. AIDS, Drug s and Sexual Risk: Lives in the Balance; Open University Press: Buckingham, 1992.

37. Coutinho, R.A. HIV and Hepatitis $C$ among Injecting Drug Users: Success in Preventing HIV has not been Mirrored for Hepatitis C. Br. Med. J. 1998, 317, 424-425.

38. British Medical Association. The Misuse of Drugs; Harwood Academic Publishers:

Amsterdam, 1997.

39. Wodak, A. The Connection between Drugs Policy and HIV Infection in Injecting Drug Users. In Reducing the Harm from Drug Use; O'Hare, P., Newcombe, R., Buning, E., Drucker, E., Matthews, A., Eds.; Routledge: London, 1992; 49-61.

40. Des Jarlais, D.C.; Choopanya, K.; Vanichseni, S.; Friedmann, P.; Raktham, S.; Friedman, S.R. High HIV Seroprevalence Epidemics among Injecting Drug Users: New York City and Bangkok. J. Drug Issues 1997, 27, 87-95.

41. Conviser, R.; Rutledge, J.H. Can Public Polices Limit the Spread of HIV among IV Drug Users? J. Drug Issues 1989, 19, 113-128. 42. Robertson, R. The Arrival of HIV. In Heroin Addiction and Drug Policy: The British System; Strang, J., Gossop, M., Eds.; Oxford University Press: Oxford, 1994, 91-101.

43. Gossop, M. Living with Drugs; 4th Ed. Ashgate, Aldershot, 1998. 44. Naik, T.N.; Sarker, S.; Singh, H.L.; Bhunia, S.C.; Singh, Y.I.; Singh, P.K.; Pal, S.C. Intravenous Drug Users-A New High Risk Group for HIV Infection in India. AIDS 1991, 5, 117-118.

45. Wodak, A.; Lurie, P. A Tale of Two Countries: Attempts to Control HIV among Injecting Drug Users in Australia and the United States. J. Drug Issues 1996,27 , 117-134. 
46. Hurley, S.F. Effectiveness of Needle-exchange Programmes for Prevention of HIV Infection. Lancet 1997, 349, 1797.

47. United Nations International Drug Control Programme. World Drug Report; Oxford University Press: Oxford, 1997.

48. Robson, P.; Bruce, M. A Comparison of 'Visible' and 'Invisible' Users of Amphetamine, Cocaine and Heroin: Two Distinct Populations? Addiction 1997, 92, 1729-1736.

\section{THE AUTHOR}

Karen McElrath received her Ph.D. in criminology from Florida State University. She and Kieran McEvoy served as co-principal investigators of a major qualitative study of Ecstasy use in Northern Ireland. Her current research interests focus on cross-cultural comparisons of drug use and/or HIV. She is the editor of the book, HIV and AIDS: A Global View (Greenwood, 2001), and is co-author of a forthcoming book on the social context of drug taking (Polity). 